\title{
Correction to: Histogram analysis based on multi-parameter MR imaging as a biomarker to predict lymph node metastasis in T3 stage rectal cancer
}

\author{
Yang Zhou ${ }^{1 \dagger}$, Rui Yang ${ }^{2 \dagger}$, Yuan Wang ${ }^{2}$, Meng Zhou ${ }^{2}$, Xueyan Zhou ${ }^{3}$, JiQing Xing ${ }^{4}$, Xinxin Wang ${ }^{1 *}$ and \\ Chunhui Zhang ${ }^{2 *}$
}

\section{Correction to: BMC Medical Imaging (2021) 21:176}

https://doi.org/10.1186/s12880-021-00706-0

Following the publication of the original article [1], the authors requested to amend the article title from "Histogram analysis of diffusion-weighted magnetic resonance imaging as a biomarker to predict LNM in T3 stage rectal carcinoma" to "Histogram analysis based on multiparameter MR imaging as a biomarker to predict lymph node metastasis in T3 stage rectal cancer".

The correct title is included in this Correction and has already been updated in the original article.

\section{Author details}

'Department of Radiology, Harbin Medical University Cancer Hospital, No. 150, Haping Road, Nangang District, Harbin 150001, Heilongjiang Province, China. ${ }^{2}$ Department of Gastrointestinal Medical Oncology, Harbin Medical University Cancer Hospital, Heilongjiang Cancer Institute, No.150 Haping Road, Nangang
District, Harbin 150081, Heilongjiang Province, China. ${ }^{3}$ School of Technology, Harbin University, Harbin, Heilongjiang Province, China. ${ }^{4}$ Department of Physical Education, Harbin Engineering University, Harbin 150001, Heilongjiang Province, China.

Published online: 01 March 2022

\section{Reference}

1. Zhou Y et al. Histogram analysis based on multi-parameter MR imaging as a biomarker to predict lymph node metastasis in T3 stage rectal cancer. BMC Med Imaging. 2021;21:176. https://doi.org/10.1186/ s12880-021-00706-0.

\section{Publisher's Note}

Springer Nature remains neutral with regard to jurisdictional claims in published maps and institutional affiliations.

${ }^{1}$ Department of Radiology, Harbin Medical University Cancer Hospital, No. 150, Haping Road, Nangang District, Harbin 150001, Heilongjiang Province, China

${ }^{2}$ Department of Gastrointestinal Medical Oncology, Harbin Medical University Cancer Hospital, Heilongjiang Cancer Institute, No.150 Haping Road, Nangang District, Harbin 150081, Heilongjiang Province, China Full list of author information is available at the end of the article original author(s) and the source, provide a link to the Creative Commons licence, and indicate if changes were made. The images or other third party material in this article are included in the article's Creative Commons licence, unless indicated otherwise in a credit line to the material. If material is not included in the article's Creative Commons licence and your intended use is not permitted by statutory regulation or exceeds the permitted use, you will need to obtain permission directly from the copyright holder. To view a copy of this licence, visit http://creativecommons.org/licenses/by/4.0/. The Creative Commons Public Domain Dedication waiver (http://creativecommons.org/publicdomain/zero/1.0/) applies to the data made available in this article, unless otherwise stated in a credit line to the data. 